\title{
Continuous intra-gastral monitoring of intra-abdominal pressure in critically ill children: a validation study
}

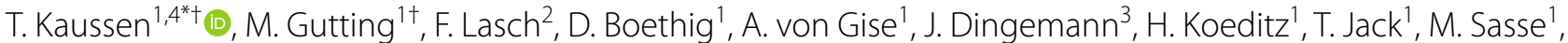 \\ P. Beerbaum ${ }^{1}$ and M. Boehne
}

\section{*Correspondence:}

Kaussen.torsten@mh-

hannover.de

${ }^{\dagger}$ T. Kaussen and M. Gutting contributed equally to this work

${ }^{4}$ Department of Paediatric Cardiology and Intensive Care Medicine, Hannover Medical School, University Children's Hospital,

Carl-Neuberg-Str. 1, 30625 Hannover, Germany Full list of author information is available at the end of the article

\begin{abstract}
Background: In critically ill children, detection of intra-abdominal hypertension $(\mathrm{IAH}>10 \mathrm{mmHg})$ and abdominal compartment syndrome $(\mathrm{ACS}=\mid \mathrm{AH}+$ organ dysfunction) is paramount and usually monitored through intra-vesical pressures (IVP) as current standard. IVP, however, carries important disadvantages, being time-consuming, discontinuous, with infection risk through observer-dependent manipulation, and illdefined for catheter sizes. Therefore, we sought to validate air-capsule-based measurement of intra-gastric pressure (ACM-IGP).
\end{abstract}

Methods: We prospectively compared ACM-IGP with IVP both in vivo and in vitro (water column), according to Abdominal-Compartment-Society validation criteria. We controlled for patient age, admission diagnosis, gastric filling/propulsive medication, respiratory status, sedation levels and transurethral catheters, all influencing intraabdominal pressure (IAP).

Results: In tertiary care PICU setting, finally, $n=97$ children were enrolled (median age, 1.3 years [range 0 days-17 years], LOS-PICU 8.0 [1-332] days, PRISM-III-Score 13 [0-35]). In $n=2.770$ measurements pairs, median IAP was $6.7[0.9-23.0] \mathrm{mmHg}, n=38$ (39\%) children suffered from IAH> $10 \mathrm{mmHg}, n=4$ from ACS. In vitro against water column, ACM-IGP correlated perfectly $\left(r^{2} 0.99\right.$, mean bias $-0.1 \pm 0.5 \mathrm{mmHg}$, limits of agreement (LOA) $-1.1 /+0.9$, percentage error [PE] 12\%) as compared with IVP $\left(r^{2} 0.98\right.$, bias $+0.7 \pm 0.6 \mathrm{mmHg}$, LOA $\left.-0.5 /+1.9, \mathrm{PE} 15 \%\right)$. With larger IVP catheters at higher pressure levels, IVP underestimated pressures against water column. In vivo, agreement between either technique was strong $\left(r^{2} 0.95\right.$, bias $0.3 \pm 0.8 \mathrm{mmHg}, \mathrm{LOA}$ $-1.3 /+1.9 \mathrm{mmHg}$, PE 23\%). No impact of predefined control variables on measurement agreement was observed.

Conclusions: In a large PICU population with high IAH prevalence, ACM-IGP agreed favourably with IVP. More widespread usage of ACM-IGP may improve detection rates of ACS in critically ill children.

Trial registration WHO-ICTRP-No. DRKS00006556 (German Clinical Trial Register). Registered 12th September 2014, URL: https://www.drks.de/drks_web/navigate.do?navig ationld=trial.HTML\&TRIAL_ID=DRKS00006556 author(s) and the source, provide a link to the Creative Commons licence, and indicate if changes were made. The images or other third party material in this article are included in the article's Creative Commons licence, unless indicated otherwise in a credit line to the material. If material is not included in the article's Creative Commons licence and your intended use is not permitted by statutory regulation or exceeds the permitted use, you will need to obtain permission directly from the copyright holder. To view a copy of this licence, visit http:// creativecommons.org/licenses/by/4.0/. 
Keywords: Intra-abdominal pressure measurement, Intra-gastric pressure measurement, Air capsule nasogastric tube, Intra-abdominal hypertension, Abdominal compartment syndrome, Paediatric intensive care

\section{Background}

Abdominal compartment syndrome (ACS) in children is defined as sustained intraabdominal hypertension (IAH, intra-abdominal pressure (IAP) $>10 \mathrm{mmHg}$ ) accompanied with organ dysfunction (new or deteriorating) [1]. Delay in recognition or treatment may increase the mortality of ACS up to $90 \%[2,3]$. ACS occurs in the context of abdominal disease, burns, trauma, sepsis or systemic inflammation. More specifically in paediatrics, congenital abdominal wall or diaphragm defects, organ transplantation and necrotizing enterocolitis may be predisposing disorders [4].

According to Abdominal Compartment Society (WSACS; formerly: World Society of Abdominal Compartment Syndrome) recommendations, measurement of intra-vesical pressure (IVP) is the current reference method of IAP determination in children [1]. In clinical practice, regular measurement of IAP remains the exception due to the fact that IVP recording is known to be time-consuming and observer-dependent as it requires manual handling, with associated work load, source of sampling error and risk of urinary tract infection [4]. Moreover, IVP measures discontinuously and therefore may not capture acute IAP changes. Experienced clinicians rely on their clinical "semi-quantitative" estimation of IAP through palpation. Unfortunately, this practice has been shown to only poorly correlate with quantitative IAP measurement $[5,6]$ and cannot replace it $[7,8]$.

Recently, an air-capsule-based measurement of intra-gastric pressure (ACM-IGP) has become available for continuous, fully automated, operator-independent IAP monitoring via a customized nasogastric tube (Fig. 1). This technique works through compression of an air-filled capsule with the pressure transmitted through an additional lumen of a nasogastric tube to an outside monitor. While increasingly used in the adult ICU medicine, the ACM-IGP technique has never been formally validated according to WSACS criteria, and certainly not in paediatric intensive care medicine (Additional file 1: Table S1) [9-11].

Therefore, we conducted a prospective, single-centre cohort study aiming to validate for the first time IAP measurements by ACM-IGP against IVP (reference method), utilizing all criteria for method validation as required by WSACS, both under initial steady-state conditions as well as longitudinally during the ICU stay. For both the initial and the longitudinal comparisons of ACM-IGP versus IVP, we explored the impact of prognostic variables of IAP measurement agreement, such as age, admission diagnosis, gastric filling status and gastrointestinal motility, respiratory status, sedation levels and IVP catheter. Moreover, we designed an in vitro experiment to investigate accuracy and precision of both methods using various catheter sizes against water column pressure recording representing a gold standard.

\section{Material and methods}

\section{Study design}

This prospective, longitudinal, observational single-centre study was conducted at the interdisciplinary PICU of Hannover Medical School (MHH) between January and 

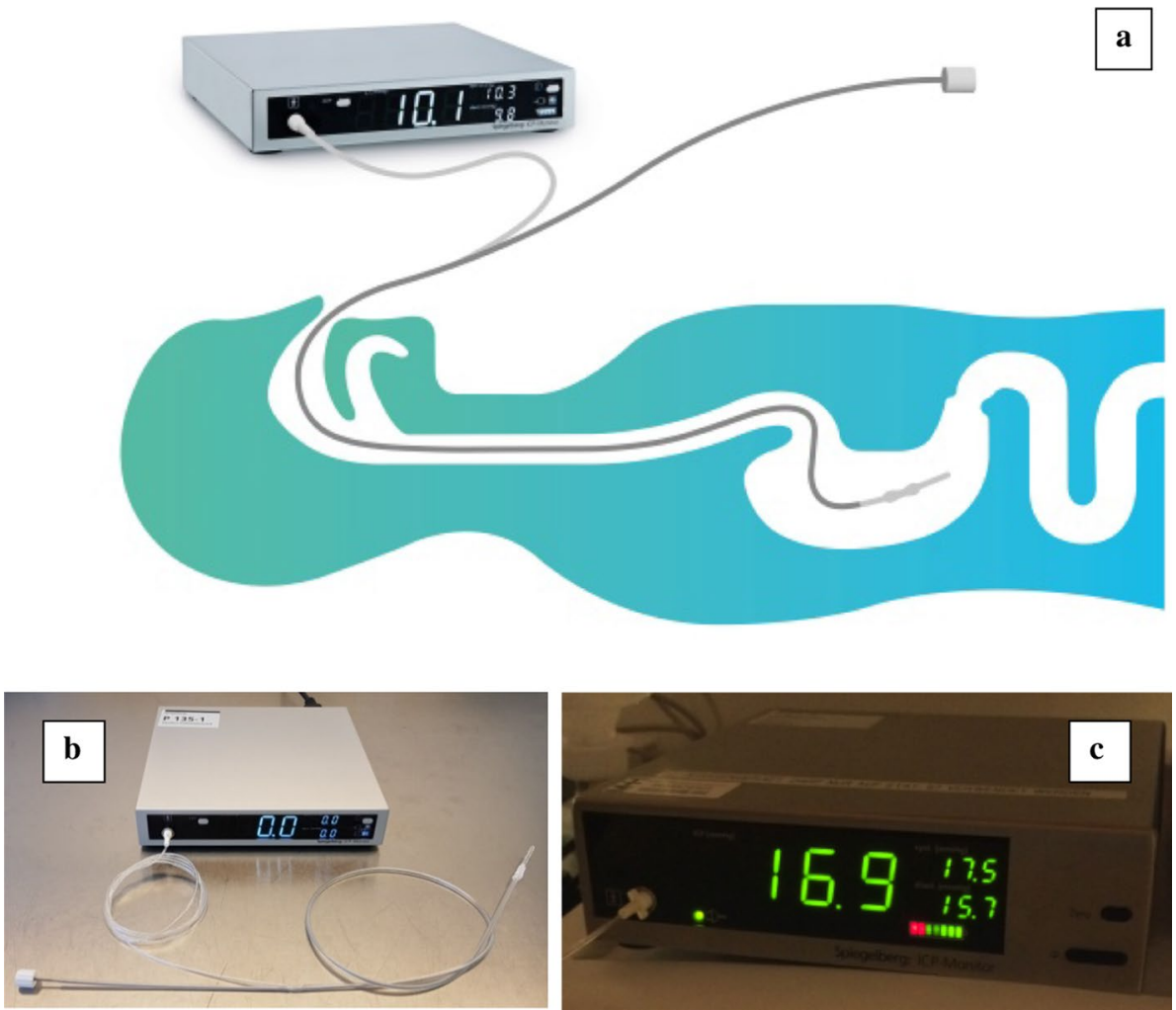

Fig. 1 Illustration of air-capsule-based intra-abdominal pressure measurement system (ACM-IGP). a Schematic illustration of the customized catheter of the air-capsule-based measurement of intra-gastric pressure (ACM-IGP) system, which is equivalent to a special double-lumen $9 F$ nasogastric tube, inserted into the stomach and connected to an ACM-IGP monitor (Illustration courtesy of Spiegelberg Company, Hamburg, Germany). The IAP normally undulates breath-synchronously (here: minimum $9.8 \mathrm{mmHg}$ in expiration, maximum $10.3 \mathrm{mmHg}$ in inspiration and $10.1 \mathrm{mmHg}$ on average). Respiratory variations are considered as a quality criterion for IAP measurement; their absence indicates a malposition of the ACM-IGP or bladder catheter and usually requires their reinsertion. The insertion of an ACM-IGP catheter does not differ from that of a conventional nasogastric tube and is theoretically associated with a similar risk profile (malposition with aspiration, pneumonia, pneumothorax and esophageal or gastric perforation) $[23,24]$. In patients beyond infancy, the placement is facilitated by an intraluminal guidewire provided by the manufacturer. In neonates and infants, the ACM-IGP catheter was placed without a guidewire, as the narrow bendig of the rigid guidewire in the pharynx hampers a later removal in this age group. All currently available ACM-IGP catheters do not have a radiopaque contrast. Therefore, the gastric catheter location was additionally verified by abdominal sonography in the present study. $\mathbf{b}$ Figure illustrates the ACM-IGP catheter connected to the ACM-IGP monitor. On the right side, the white, thin-skinned air capsule (sized $10 \times 3 \times 2.3 \mathrm{~mm}$ ) is displayed at the gastric end of the ACM-IGP catheter, which is used for IAP measurement. The opposite side is connected to the pressure transducer on the left front of the ACM-IGP monitor. In the left lower margin the guide wire for insertion of the ACM-IGP catheter is displayed on the aboral end of the second lumen. Calibration and "zeroing" of the ACM-IGP system are fully automatic and repeated once per hour in the operating mode. During the continuous IAP measurement, the air capsule is filled with a defined air volume of $0.05-0.10 \mathrm{ml}$. Any pressure applied to the air capsule from outside is registered by the pressure transducer in the monitor and displayed as IAP with a precision of one decimal. $\mathbf{c}$ Illustration of a representative ACM-IGP measurement in a critically ill child with intra-abdominal hypertension (IAH) grade III $(\mathrm{IAP}=16.9 \mathrm{mmHg})$. Please note that the displayed pressures with the minimum in exspiration $(15.7 \mathrm{mmHg})$ and maximum in inspiration $(17.5 \mathrm{mmHg}$ ) represent respiratory variations of IAP

August 2015. The clinical trial was approved by the local Ethics Committee (MHH-No. 6677) and registered internationally (WHO-ICTRP-No. DRKS00006556). 


\section{Patient enrolment}

All children admitted to PICU with a transurethral catheter and need for a nasogastric tube fulfilled the inclusion criteria and were enrolled provided that a steady-state IAP measurement condition could be achieved within the first $24 \mathrm{~h}$ after patient enrolment (see below). Exclusion criteria were premature birth, any diseases or malformations of the nasopharynx, upper gastrointestinal or urinary tract. Before enrolment, written informed consent was obtained from legal representatives.

\section{Clinical data collection}

For each patient, demographic data at admission, diagnosis and length of stay at PICU (LOS-PICU) were recorded. To evaluate potential influencing factors on IAP measurement agreement between IVP and ACM-IGP, additional clinical data (patient age, admission diagnosis, gastric filling/propulsive medication, respiratory status, analgosedation levels, transurethral catheter type and size) were collected (for details refer to Additional file 1). Paediatric Risk of Mortality III Score (PRISM-III) was calculated on the first day of enrolment [12].

\section{Intra-abdominal pressure measurement (IAP)}

Intra-vesical pressure (IVP) and intra-gastric pressure (IGP) measurements are considered indirectly determined correlates of intra-abdominal pressure (IAP). According to WSACS, an IAH was classified as IAP > $10 \mathrm{mmHg}$ in at least two consecutive IVP measurements, an abdominal compartment syndrome (ACS) as IAH accompanied with organ dysfunction (new or deteriorating) [1, 13]. IAH was classified into four grades according to child-adapted WSACS criteria $\left(\mathrm{I}^{\circ}\right.$ : IAP $>10-12 \mathrm{mmHg}, \mathrm{II}^{\circ}$ : 13-15 mmHg, III : 16-18 mmHg, $\mathrm{IV}^{\circ}:>18 \mathrm{mmHg}$ ) [4].

\section{Measurement practice}

Based upon the modified Kron technique, IVP measurements were performed using a transurethral catheter according to WSACS recommendation (emptying the bladder, filling with $1 \mathrm{ml} / \mathrm{kg} \mathrm{BW}$ normal saline [min. $3 \mathrm{ml}$, max. $25 \mathrm{ml}$ ] under aseptic conditions, waiting for at least 2 min to allow equilibration) with the midaxillary level as zero reference (clinical standard; [1, 14]). IVP is transmitted from the end-open transurethral catheter through the continuous liquid column in the catheter lumen to an outside pressure transducer (Codan, Germany). Transurethral catheters for IVP measurement were sizewise adjusted for weight and age (Norta-Nelaton 6-16 Charriére (Ch.) diameter, BSNmedical Company, Germany). For anatomical reasons, gastric tubes were used alternatively in small neonates (Flocare pursoft tube, $5 \mathrm{Ch}$., Nutricia Medical Devices, Netherlands).

IGP was determined by air-capsule-based measurement (ACM-IGP, Spiegelberg company, Germany) using a commercially available 9 French double-lumen nasogastric tube catheter with one separate lumen for continuous IGP measurement (please refer to Fig. 1) $[9-11,15,16]$. A thin air capsule (sized $10 \times 3 \times 2.3 \mathrm{~mm}$ ) at the tip of the catheter is connected to a pressure transducer of a bedside ACM-IGP monitor. For IAP measurement, the air capsule is filled with a defined air volume of 
0.05-0.10 ml through the ACM-IGP catheter lumen. Any variation of external pressure is immediately transduced via the air capsule to the monitor and converted into an electrical signal. The exact underlying technical process for IAP quantification is proprietary and at the discretion of the manufacturer.

The ACM-IGP system has been approved and CE-certified as an independent medical device for many years; all necessary tests were performed and its biocompatibility and endurance were confirmed ("shelf test"). The shelf life of the polyurethane catheter is specified by the manufacturer for 30 days.

For anatomical reasons, ACM-IGP catheters can generally be used for patients with a body weight of $3 \mathrm{~kg}$ or above. All ACM-IGP catheters were inserted nasally or perorally like conventional nasogastric tubes.

Using sonography, the correct positions of ACM-IGP and transurethral catheters were checked at least daily and additionally whenever ACM-IGP or IVP measurements showed no respiratory undulations. Such respiratory variations are considered as a quality criterion for IAP measurement; their absence indicate a malposition of the ACM-IGP or bladder catheter and usually require their reinsertion (please refer to Fig. 1).

\section{Primary endpoint: initial agreement of ACM-IGP with IVP under steady-state conditions}

For the primary goal-validation of ACM-IGP vs. IVP-the first simultaneous ACM-IGP and IVP measurements, once a steady-state condition of at least 5 min was achieved, were used for primary endpoint. Steady-state was defined as stable vital signs and analgosedation level (i.e. no movement of the patient, no change in the patient's level of consciousness, stable heart rate and arterial pressure). Typically, the steady state was reached within the first hour of admission. For each patient, the first episode reaching the steady-state criteria was independently identified by two blinded, experienced paediatric intensive care physicians. In case of disagreement, a consensus was achieved with a third senior paediatric intensive care physician and the episode was allocated without ambiguity. All investigators were blinded for ACM-IGP and IVP measurements results. If a patient did not fulfil the steady-state criteria within $24 \mathrm{~h}$ after enrolment, a valid measurement could not be obtained and the patient was excluded from the study.

\section{Secondary endpoint of agreement and explorative analysis of confounders under real-life conditions during the ICU stay}

Following these primary comparison, all patients underwent longitudinal IAP measurements that were recorded simultaneously once per hour during daytime, for both evaluation of agreement and for explorative analyses investigating the potential impact of prognostic variables. Data were collected until either discharge from PICU, removal of IVP or ACM-IGP catheter, whichever came first. For these repeated measurements, taken during the patient's recovery under reduced sedation, measurements were included in the analysis as long as there was no agitation and/or mass movement during recording. Additionally, measurements taken during ward rounds, dressing changes, rehabilitative therapies and other examinations or interventions were excluded. 


\section{In vitro measurements}

Comparable container models have been described earlier [9, 11, 17]. For details regarding the in vitro experimental set-up, refer to Additional file 1: Fig S1.

\section{Data processing and statistical analysis}

Clinical data were recorded in a digital patient data monitoring system (Copra ${ }^{\circledR}$ Systems, Berlin, Germany), transferred to an Excel ${ }^{\circledR} 2016$ database (Microsoft ${ }^{\circledR}$ Corporation, Redmond, USA) and analysed with SPSS ${ }^{\circledR}$ Statistics V22.0 (IBM ${ }^{\circledR}$, Armonk, North Castle, USA).

For in vivo and in vitro measurements, data of different IAP measurements methods were compared by linear regression analysis. Shapiro-Wilk testing revealed a non-normal data distribution; therefore, correlation analysis was performed by Spearman's coefficient of determination. WSACS recommendations were applied to assess interchangeability of IAP measurement methods according to Bland-Altman (mean bias, limits of agreement [LOA], precision (standard deviation [SD] of the Bias) and percentage error [PE, LOA/mean IAP of both methods]) $[18,19]$. Furthermore, a mean absolute percentage error (MAPE \pm SD) was calculated according to de Myttenaere et al. [20].

\section{Primary endpoint analysis}

For the initial clinical baseline validation, the first pair of simultaneous IVP and ACMIGP measurements under steady-state conditions of each enrolled subject was taken. To compare IVP and ACM-IGP measurements, the mean $\mu_{\text {diff }}$ of the pairwise difference $\operatorname{diff}_{i}=\mathrm{ACMIGP}_{i}-\mathrm{IVP}_{i}$ between IVP and ACM-IGP measurements was calculated (where the subscript $i$ represents patient $i$ ).

To assess the agreement between both independent investigators, the pairwise differences (see above) for each patient were compared. To compare investigators A and B, the patient-specific difference between investigators was calculated as $\operatorname{diff}_{i}^{\mathrm{A}}-\operatorname{diff}_{i}^{\mathrm{B}}$, where $\operatorname{diff}_{i}^{\mathrm{A}}$ represents the difference between between IVP and ACM-IGP in patient $i$ based on the assessment of investigator A. Using this difference, the mean difference between investigators was calculated as mean mean $\left(\operatorname{diff}_{\mathrm{i}}^{\mathrm{A}}-\operatorname{diff}_{\mathrm{i}}^{\mathrm{B}}\right)$ and the mean squared error as $\operatorname{mean}\left(\left(\operatorname{diff}_{\mathrm{i}}^{\mathrm{A}}-\operatorname{diff}_{\mathrm{i}}^{\mathrm{B}}\right)^{2}\right)$.

\section{Secondary endpoint analyses}

For the longitudinal analysis of agreement during patient recovery, the initial and all pairs of simultaneous measurements were used. For the latter, we assumed that all measurement pairs were independent, because patient conditions varied much during ICU stay, regarding vital signs, vascular pressures, respiratory status and sedation levels.

In further exploratory analyses, the impact of clinical factors potentially influencing ACM-IGP agreement were evaluated separately for both the first pair of measures and for all longitudinal pairs of simultaneous IVP and ACM-IGP measurements. 


\section{Results}

In vivo analysis

\section{Patient characteristics}

A population of $n=106$ children met the inclusion criteria. Of those, $n=9$ children did not fulfil steady-state criteria and were excluded from further analysis. Finally, $n=97$ children (39\% female) with a median age (range) of 1.3 years ( 0 days -17.0 years) could be enrolled (Table 1). Median PRISM-III score at admission was 13 (0-35), the overall mortality rate $8 \%$ and median LOS-PICU 8 (1-332) days. Admission diagnoses reflected a broad range of both post-operative and non-surgical entities as outlined in Table 2 . As many as $n=38$ of the 97 children (39\%) suffered from IAH ( $\mathrm{I}^{\circ}: n=27$ [28\%], $\mathrm{II}^{\circ}: n=9$ [9\%], III $: n=2[2 \%])$, and $n=4$ children (4\%) showed ACS. During their stay on PICU, $n=92$ (95\%) children were temporarily mechanically ventilated. In addition to analgosedation, $n=13$ (13\%) patients received permanent neuromuscular blocking agents. About $50 \%$ of the children showed reduced peristalsis and about $1 / 3$ were affected by gastric residuals, gastroparesis or subileus. $N=14$ children (14\%) required a temporary openabdomen treatment.

Table 1 Patient demographics

\begin{tabular}{|c|c|}
\hline Parameter & $\begin{array}{l}\text { Number (\%) } \\
\text { or median } \\
\text { (range) }\end{array}$ \\
\hline Enrolled patients & $97(100 \%)$ \\
\hline Female & $38(39 \%)$ \\
\hline Age (years) & $1.3(0.0-17.0)$ \\
\hline \multicolumn{2}{|l|}{ Age category } \\
\hline Neonates & $12(12 \%)$ \\
\hline Infants & $29(29 \%)$ \\
\hline Toddlers & $26(27 \%)$ \\
\hline School children & $16(17 \%)$ \\
\hline Adolescents & $14(14 \%)$ \\
\hline $\mathrm{BMI}\left(\mathrm{kg} / \mathrm{m}^{2}\right)$ & $15.6(8.9-33.0)$ \\
\hline Length of stay at PICU (days) & $8(1-332)$ \\
\hline \multicolumn{2}{|l|}{ Admission diagnoses } \\
\hline Cardiac and post-cardiac surgery & $46(47 \%)$ \\
\hline Paediatric surgical & $26(27 \%)$ \\
\hline Neurosurgical & $9(9 \%)$ \\
\hline Traumatological & $8(8 \%)$ \\
\hline \multicolumn{2}{|l|}{ Non-surgical (internal) } \\
\hline Pulmonology & $3(3 \%)$ \\
\hline Oncologic & $3(3 \%)$ \\
\hline Infectious (sepsis) & $2(2 \%)$ \\
\hline PRISM-III-score (first day of enrolment) & $13.0(0.0-35.0)$ \\
\hline Prevalence of IAH overall & $38(39 \%)$ \\
\hline IAH grade I (10-12 mmHg) & $27(28 \%)$ \\
\hline IAH grade I| (13-15 mmHg) & $9(9 \%)$ \\
\hline $\mid \mathrm{AH}$ grade || $\mid(\geq 16 \mathrm{mmHg})$ & $2(2 \%)$ \\
\hline Prevalence of ACS & $4(4 \%)$ \\
\hline Mortality & $8(8 \%)$ \\
\hline
\end{tabular}

$B M I$ body mass index, PICU paediatric intensive care unit, PRISM-III-score paediatric risk of mortality score III [12], IAH intraabdominal hypertension, $A C S$ abdominal compartment syndrome 


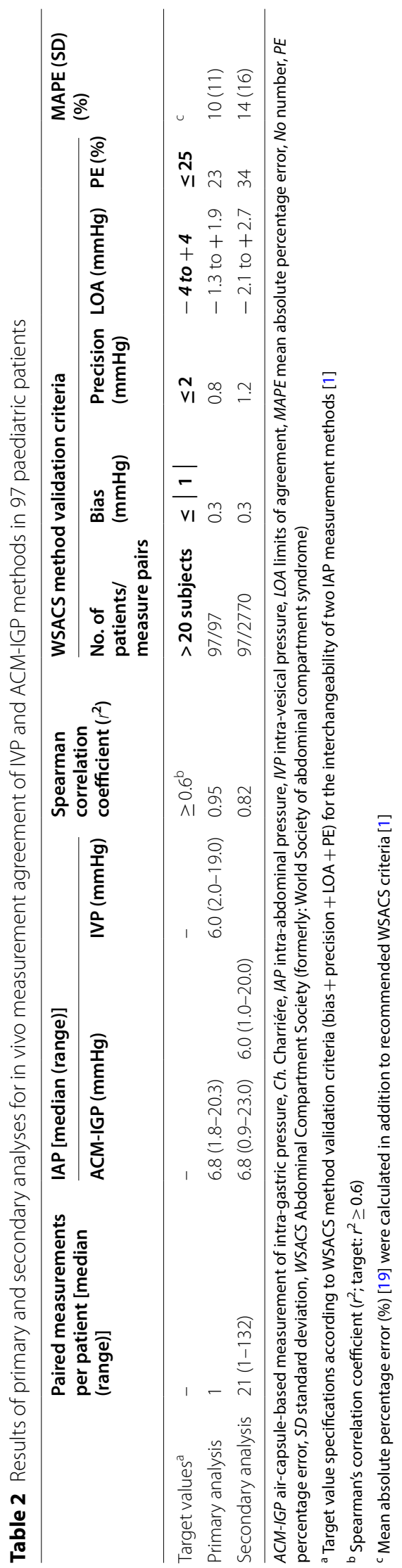


Neither infections nor perforations of the upper digestive or urogenital tract were diagnosed as adverse events during IAP measurements.

\section{IAP measurements}

Primary analysis of first paired measurement (IVP versus ACM-IGP) The first episode patients fulfilling the steady-state criteria was independently identified equally in 62 of 97 cases $(64 \%)$ by the investigators; in 35 cases (36\%) a consensus was achieved with a third investigator. The mean difference between the paired simultaneous IVP and ACMIGP measurements selected by each investigator was $-0.03 \pm 1.0 \mathrm{mmHg}$ and the mean squared error was $1.0 \pm 3.9 \mathrm{mmHg}^{2}$. Steady-state criteria were achieved in median after 2 (range 1-14) hours following enrolment.

The first $n=97$ measurement pairs during steady state were included in the primary analysis. Median IAP (range) by IVP was $6.0(2.0-19.0) \mathrm{mmHg}$ and $6.8(1.8-20.3)$ mmHg by ACM-IGP. A strong correlation $\left(r^{2}=0.95\right)$ was observed between both methods. Bland-Altman analysis between IVP and ACM-IGP revealed a mean IAP $( \pm$ SD) of $7.1 \pm 3.4 \mathrm{mmHg}$ for both methods, a mean bias \pm precision of $0.3 \pm 0.8 \mathrm{mmHg}$ with $95 \%$ limits of agreement (LOA) of -1.3 and $1.9 \mathrm{mmHg}$ (Fig. 2a, Table 2). Percentage error (PE) was $23 \%$ and mean absolute percentage error (MAPE) was $10 \pm 11 \%$.

Secondary analysis of longitudinal data (IVP versus ACM-IGP) Totally, $n=4851$ simultaneous IVP and ACM-IGP measurements were longitudinally performed in $n=97$ subjects. $N=2081$ measurements were recorded under agitation, mass movements, etc., and excluded from further analysis.

Finally, $n=2770$ longitudinal measurement pairs with in median 21 (range 1-132) measurement pairs per child were recorded over 8 days in median (1-332) and further evaluated (Table 2). Median IAP (range) by IVP was $6.0(1.0-20.0) \mathrm{mmHg}$, and 6.8 (0.9-23.0) $\mathrm{mmHg}$ by ACM-IGP. Spearman's correlation coefficient between both methods was $r^{2}=0.82$. The Bland-Altman analysis revealed a mean IAP of $7.1 \pm 2.6 \mathrm{mmHg}$ for both methods, a mean bias \pm precision of $0.3 \pm 1.2 \mathrm{mmHg}$, with LOA of -2.1 and $2.7 \mathrm{mmHg}$ (Table 2). The PE was $34 \%$, MAPE was $14 \pm 16 \%$.

Explorative analyses for prognostic factors The exploratory analyses of both, the first and the longitudinal paired measurements did not reveal any clinically relevant confounding factors with regard to patient age, respiratory status, analgosedation level, gastrointestinal motility and admission diagnosis (Additional file 1: Tables S2, S3).

\section{In vitro measurements}

In the container model, 86 single measurements were performed in each of the four different test series. Thus, in total 344 measurements were compared between ACM-IGP versus water columns, IVP versus water columns and ACM-IGP versus IVP (Table 3).

The overall agreement between the height of the water column and pressures recorded by ACM-IGP $\left(r^{2} 0.99\right.$, mean bias \pm precision $-0.1 \pm 0.5 \mathrm{mmHg}$, LOA -1.1 to $0.9 \mathrm{mmHg}$, PE $12 \%$, MAPE $9 \pm 17 \%)$ and IVP technique $\left(r^{2} 0.98\right.$, mean bias \pm precision $+0.7 \pm 0.6 \mathrm{mmHg}$, LOA -0.5 to $1.9 \mathrm{mmHg}$, PE $15 \%$, MAPE $16 \pm 17 \%)$ was excellent 


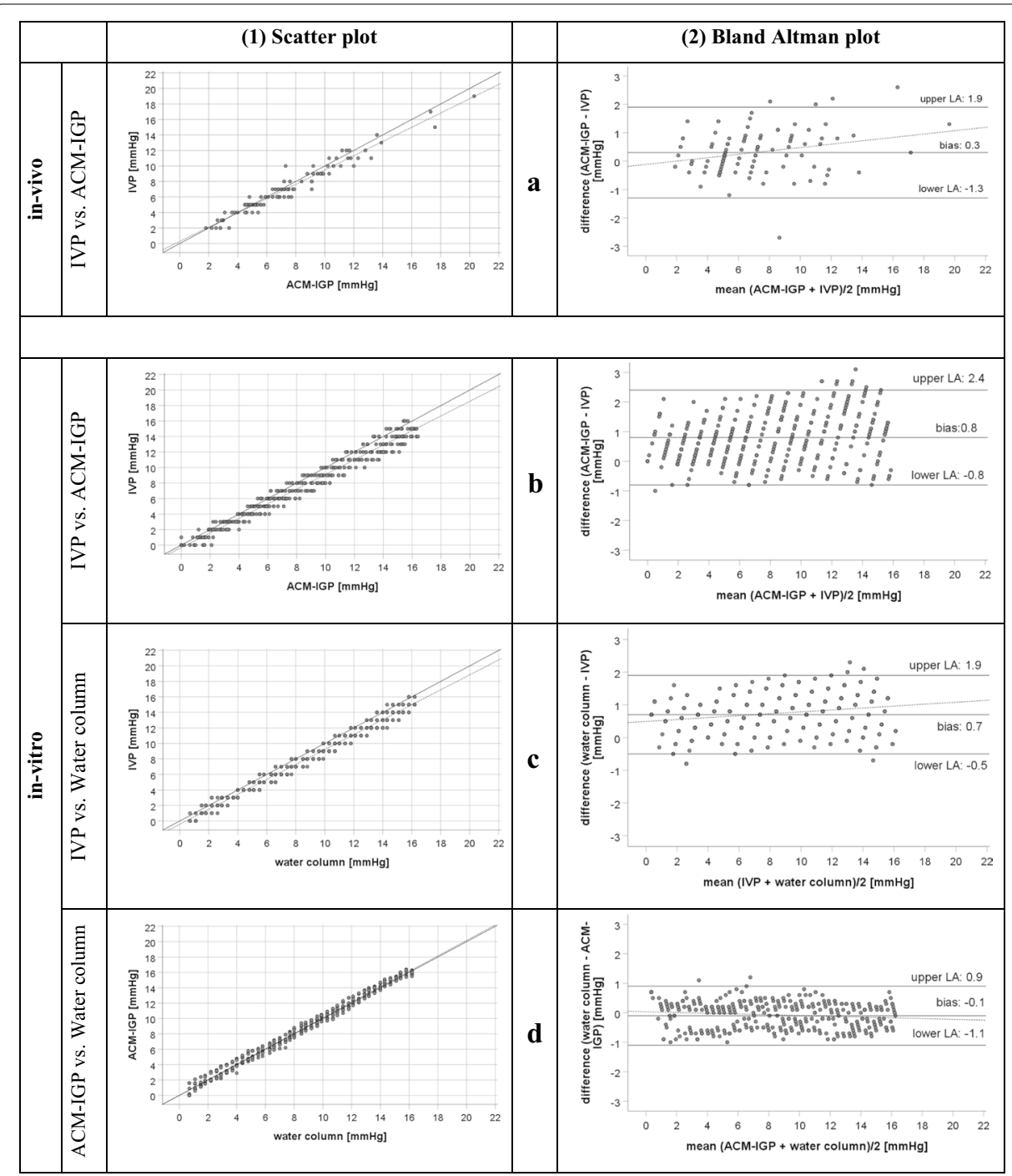

Fig. 2 In vivo and in vitro measurements. Presentation of measurement agreement between IVP and ACM-IGP measurements in vivo (a) and in vitro (b-d). a Scatter plot and Bland-Altman plot of in vivo measurements. a1 Scatter plot of paired IAP measurements obtained by novel ACM-IGP and IVP (reference method) with the solid line representing linear regression and the dashed line representing the line of identity. a2 Bland-Altman plot of IVP and ACM-IGP. Mean bias \pm precision between IVP and ACM-IGP was $0.3 \pm 0.8 \mathrm{mmHg}$; limits of agreement (LOA) were -1.3 to $1.9 \mathrm{mmHg}$. The dashed line represents the best-fit straight line, which increases slightly with rising IAP. b-d Scatter plots and Bland-Altman plots of in vitro measurements in a container model. In all scatter plots the solid line is representing linear regression and the dashed line the line of identity. b1 Scatter plot of paired pressure measurements obtained by IVP and ACM-IGP. b2 Bland-Altman plot: Mean bias \pm precision was $0.8 \pm 0.8 \mathrm{mmHg}$; LOA were -0.8 to $2.4 \mathrm{mmHg}$. The dashed line represents the best-fit straight line, which is parallel to mean bias. $\mathbf{c 1}$ Scatter plot of paired pressure measurements obtained by IVP and water column (gold standard). c2 Bland-Altman plot: Mean bias \pm precision was $0.7 \pm 0.6 \mathrm{mmHg}$; LOA were -0.5 to $1.9 \mathrm{mmHg}$. The dashed best-fit straight line increases slightly with rising pressures. d1 Scatter plot of paired pressure measurements obtained by ACM-IGP and water column. d2 Bland-Altman plot: Mean bias \pm precision was $-0.1 \pm 0.5 \mathrm{mmHg}$; LOA were -1.1 to $0.9 \mathrm{mmHg}$. The dashed best-fit straight line increases slightly with rising pressures 
Table 3 Results of the in vitro examination of measurement agreement of IVP and ACM-IGP technique compared to a water column in a container model

\begin{tabular}{|c|c|c|c|c|c|c|c|c|c|}
\hline \multirow{3}{*}{$\begin{array}{l}\text { Experimental } \\
\text { arrangement }\end{array}$} & \multirow[b]{3}{*}{$\begin{array}{l}\text { Target } \\
\text { values } \\
\text { according } \\
\text { to }[1]^{\mathrm{a}}\end{array}$} & \multirow{2}{*}{$\begin{array}{l}\text { Paired } \\
\text { measurements }\end{array}$} & \multirow{3}{*}{$\begin{array}{l}\text { IAP } \\
\text { mean } \\
(\mathrm{mmHg})\end{array}$} & \multirow{2}{*}{$\begin{array}{l}\text { Spearman } \\
\text { correlation } \\
\text { coefficient } \\
\left(r^{2}\right)\end{array}$} & \multicolumn{4}{|c|}{ WSACS method validation criteria } & \multirow{3}{*}{$\begin{array}{l}\text { MAPE } \\
\text { (SD) } \\
(\%)\end{array}$} \\
\hline & & & & & $\begin{array}{l}\text { Bias } \\
(\mathrm{mmHg})\end{array}$ & $\begin{array}{l}\text { Precision } \\
(\mathrm{mmHg})\end{array}$ & $\begin{array}{l}\text { LOA } \\
(\mathrm{mmHg})\end{array}$ & $\begin{array}{l}\text { PE } \\
(\%)\end{array}$ & \\
\hline & & - & & $\geq 0.6^{b}$ & $\leq|1|$ & $\leq 2$ & $\begin{array}{l}-4 \\
\text { to }+4\end{array}$ & $\leq 25$ & \\
\hline \multirow[t]{3}{*}{$\begin{array}{l}\text { Setting 1: } \\
\text { gastric tube } \\
(5 \mathrm{Ch} .)\end{array}$} & $\begin{array}{l}\text { ACM-IGP } \\
\text { vs. water } \\
\text { column }\end{array}$ & 86 & 8.4 & 0.99 & 0.1 & 0.2 & $\begin{array}{l}-0.3 \text { to } \\
0.5\end{array}$ & 5 & $6(13)$ \\
\hline & $\begin{array}{l}\text { Gastric tube } \\
(5 \text { Ch. }) \\
\text { vs. water } \\
\text { column }\end{array}$ & 86 & 8.0 & 0.99 & 0.8 & 0.3 & 0.2 to 1.4 & 8 & $17(21)$ \\
\hline & $\begin{array}{l}\text { ACM-IGP vs. } \\
\text { gastric tube } \\
(5 \mathrm{Ch} .)\end{array}$ & 86 & 8.0 & 0.99 & 0.7 & 0.4 & $\begin{array}{l}-0.1 \text { to } \\
1.5\end{array}$ & 10 & $13(14)$ \\
\hline \multirow[t]{3}{*}{$\begin{array}{l}\text { Setting } 2 \text { : } \\
\text { gastric tube } \\
\text { (8 Ch.) }\end{array}$} & $\begin{array}{l}\text { ACM-IGP } \\
\text { vs. water } \\
\text { column }\end{array}$ & 86 & 8.3 & 0.99 & 0.3 & 0.2 & $\begin{array}{l}-0.1 \text { to } \\
0.7\end{array}$ & 5 & $8(16)$ \\
\hline & $\begin{array}{l}\text { Gastric tube } \\
\text { (8 Ch.) } \\
\text { vs. water } \\
\text { column }\end{array}$ & 86 & 8.4 & 0.99 & 0.1 & 0.4 & $\begin{array}{l}-0.7 \text { to } \\
0.9\end{array}$ & 10 & $9(18)$ \\
\hline & $\begin{array}{l}\text { ACM-IGP vs. } \\
\text { gastric tube } \\
\text { (8Ch.) }\end{array}$ & 86 & 8.2 & 0.99 & -0.2 & 0.4 & $\frac{-1.0 \text { to }}{0.6}$ & 10 & $9(20)$ \\
\hline \multirow{3}{*}{$\begin{array}{l}\text { Setting 3: } \\
\text { tran- } \\
\text { surethral } \\
\text { catheter (6 } \\
\text { Ch.) }\end{array}$} & $\begin{array}{l}\text { ACM-IGP } \\
\text { vs. water } \\
\text { column }\end{array}$ & 86 & 8.5 & 0.99 & -0.1 & 0.5 & $\frac{-1.1 \text { to }}{1.1}$ & 12 & $9(13)$ \\
\hline & $\begin{array}{l}\text { Transurethral } \\
\text { catheter } \\
\text { (6 Ch.) vs. } \\
\text { water } \\
\text { column }\end{array}$ & 86 & 8.0 & 0.99 & 0.9 & 0.5 & $\begin{array}{l}-0.1 \text { to } \\
1.9\end{array}$ & 13 & $16(0)$ \\
\hline & $\begin{array}{l}\text { ACM-IGP vs. } \\
\text { tran- } \\
\text { surethral } \\
\text { catheter (6 } \\
\text { Ch.) }\end{array}$ & 86 & 8.0 & 0.99 & 0.9 & 0.5 & $\begin{array}{l}-0.1 \text { to } \\
1.9\end{array}$ & 13 & $15(12)$ \\
\hline \multirow{3}{*}{$\begin{array}{l}\text { Setting 4: } \\
\text { tran- } \\
\text { surethral } \\
\text { catheter (8 } \\
\text { Ch.) }\end{array}$} & $\begin{array}{l}\text { ACM-IGP } \\
\text { vs. water } \\
\text { column }\end{array}$ & 86 & 8.7 & 0.99 & -0.6 & 0.2 & $\begin{array}{l}-1.0 \text { to } \\
-0.2\end{array}$ & 5 & $14(22)$ \\
\hline & $\begin{array}{l}\text { Transurethral } \\
\text { catheter } \\
\text { (8 Ch.) vs. } \\
\text { water } \\
\text { column }\end{array}$ & 86 & 7.9 & 0.99 & 1.1 & 0.6 & $\begin{array}{l}-0.1 \text { to } \\
2.3\end{array}$ & 15 & $19(20)$ \\
\hline & $\begin{array}{l}\text { ACM-IGP vs. } \\
\text { tran- } \\
\text { surethral } \\
\text { catheter (8 } \\
\text { Ch.) }\end{array}$ & 86 & 8.2 & 0.99 & 1.7 & 0.6 & 0.5 to 2.9 & 15 & $27(16)$ \\
\hline
\end{tabular}


Table 3 (continued)

\begin{tabular}{|c|c|c|c|c|c|c|c|c|c|}
\hline \multirow{3}{*}{$\begin{array}{l}\text { Experimental } \\
\text { arrangement }\end{array}$} & \multirow[b]{3}{*}{$\begin{array}{l}\text { Target } \\
\text { values } \\
\text { according } \\
\text { to }[1]^{\mathrm{a}}\end{array}$} & \multirow{2}{*}{$\begin{array}{l}\text { Paired } \\
\text { measurements }\end{array}$} & \multirow{3}{*}{$\begin{array}{l}\text { IAP } \\
\text { mean } \\
(\mathrm{mmHg})\end{array}$} & \multirow{3}{*}{$\begin{array}{l}\text { Spearman } \\
\text { correlation } \\
\text { coefficient } \\
\left(r^{2}\right)\end{array}$} & \multicolumn{4}{|c|}{ WSACS method validation criteria } & \multirow{3}{*}{$\begin{array}{l}\text { MAPE } \\
(\mathrm{SD}) \\
(\%)\end{array}$} \\
\hline & & & & & $\begin{array}{l}\text { Bias } \\
(\mathrm{mmHg})\end{array}$ & $\begin{array}{l}\text { Precision } \\
(\mathrm{mmHg})\end{array}$ & $\begin{array}{l}\text { LOA } \\
(\mathrm{mmHg})\end{array}$ & $\begin{array}{l}\mathrm{PE} \\
(\%)\end{array}$ & \\
\hline & & - & & & $\leq|1|$ & $\leq 2$ & $\begin{array}{l}-4 \\
\text { to }+4\end{array}$ & $\leq 25$ & \\
\hline \multirow[t]{3}{*}{ Overall } & $\begin{array}{l}\text { ACM-IGP } \\
\text { vs. water } \\
\text { column }\end{array}$ & 344 & 8.5 & 0.99 & -0.1 & 0.5 & $\begin{array}{l}-1.1 \text { to } \\
0.9\end{array}$ & 12 & $9(17)$ \\
\hline & $\begin{array}{l}\text { IVP (transure- } \\
\text { thral cath- } \\
\text { eter + gas- } \\
\text { tric tube) } \\
\text { vs. water } \\
\text { column }\end{array}$ & 344 & 8.1 & 0.98 & 0.7 & 0.6 & $\begin{array}{l}-0.5 \text { to } \\
1.9\end{array}$ & 15 & $15(20)$ \\
\hline & $\begin{array}{l}\text { ACM-IGP vs. } \\
\text { IVP (tran- } \\
\text { surethral } \\
\text { cathe- } \\
\text { ter + gastric } \\
\text { tube) }\end{array}$ & 344 & 8.1 & 0.97 & 0.8 & 0.8 & $\begin{array}{l}-0.8 \text { to } \\
2.4\end{array}$ & 20 & $16(17)$ \\
\hline
\end{tabular}

ACM-IGP air-capsule-based measurement of intra-gastric pressure, $C h$. Charriére, IAP intra-abdominal pressure, IVP intra-vesical pressure, $L O A$ limits of agreement, MAPE mean absolute percentage error, No number, $P E$ percentage error, $S D$ standard deviation, WSACS Abdominal Compartment Society (formerly: World Society of Abdominal Compartment Syndrome)

${ }^{\text {a }}$ Target value specifications according to WSACS method validation criteria (bias + precision + LOA + PE) for the interchangeability of two IAP measurement methods [1]

${ }^{b}$ Spearman's correlation coefficient $\left(r^{2}\right.$; target: $\left.r^{2} \geq 0.6\right)$

${ }^{c}$ Mean absolute percentage error (\%; MAPE [19]) were calculated in addition to recommended WSACS criteria [1]

(Fig. 2b-d, Table 3). Pressures obtained by ACM-IGP and IVP agreed well $\left(r^{2} 0.97\right.$, mean bias \pm precision $0.8 \pm 0.8 \mathrm{mmHg}$, LOA -0.8 to $2.4 \mathrm{mmHg}$, PE $20 \%$, MAPE $15 \pm 20 \%$ ).

Interestingly, with both, gastric tubes ( 5 and $8 \mathrm{Ch}$.) and transurethral catheters ( 6 and $8 \mathrm{Ch}$.), the differences between pressures recorded by IVP technique and the height of the water column tended to increase with rising pressures (Table 3, Additional file 1: Fig. S3).

\section{Discussion}

\section{Study design and key messages}

In this study, the main objective was to validate the air-capsule-based measurement of intra-gastric pressure (ACM-IGP) in a clinical real-life paediatric ICU setting. Therefore, we conducted a prospective cross-sectional validation analysis of intra-abdominal pressure (IAP) in $n=97$ critically ill children. Notably, for the first time, the present validation study fulfilled all requested WSACS criteria for comparison of different IAP measurement methods. We were able to gather reliable data across a wide age range, extending from neonatal to adolescent age, with adequate representation of all age groups. The PRISM-III scores (median 13, maximal 35) reflect a wide range of disease severity in our population. Our validation cohort is particularly valuable due to the high prevalence of intra-abdominal hypertension (IAH) of 39\%, including IAH grade III (16-18 $\mathrm{mmHg}$ ) and IAP levels up to $23 \mathrm{mmHg}$, with abdominal compartment syndrome 
(ACS) observed in $4 \%$ of all cases (Table 1, Additional file 1: Table S2). In this demanding population, we showed that the novel measurement technique ACM-IGP, is accurate, reproducible and robust when compared to the current clinical reference, namely intravesical pressure recording (IVP).

In our longitudinal analysis performed over a period of median 8.0 days (range 1-332) yielding 2770 measurement pairs, we further investigated associated clinical factors such as age, respiration, vigilance, peristalsis, gastric residuals and motility, or admission diagnoses, that may impact on measurement agreement of IAP. We did not find a relevant impact for these potential confounders on measurement agreement of ACM-IGP.

Interestingly, our in vitro validation of gastric ACM-IGP and IVP showed that ACMIGP had an even better precision and accuracy than IVP against a water-column-based gold standard across a wide range of pressures as IVP slightly underestimated pressures particularly at higher levels, while the ACM-IGP method remained accurate. Clinically, the agreement between ACM-IGP and IVP while good in general seemed to slightly worsen at higher IAP levels.

Based on these in vitro and in vivo observations, we hypothesize that ACM-IGP may possibly be even better suited for IAP measurement, particularly in a clinical setting of high-risk for IAH.

\section{Motivation for the present study from previous work on IAP measurement}

In 1981, Wesley et al. were the first to conceptualize the use of intra-gastric pressure (IGP) for IAP measurement [21]. The authors applied a water manometer through a gastrostomy tube during congenital abdominal wall repair in premature and neonates [21]. Another technique, a water-filled nasogastric tube connected to a pressure transducer was used by Davis et al. in 2005 for IGP measurements in children [22]. IGP correlated well with IAP directly assessed via a peritoneal dialysis catheter over a physiological pressure range of 1-8 $\mathrm{mmHg}$ [22]. Schachtrupp et al. first applied the air-capsule-based measurement (ACM) catheter in an animal validation study [15]. Instead of intra-gastric application-as provided for measurements in our study - they used an intra-abdominal location [15]. IAP derived by ACM method showed a stronger correlation compared to the laparoscopic insufflator gold standard than simultaneous IVP measurements-even at extremely high IAP levels [15]. Otto and colleagues transferred this experimental approach of intra-abdominally placed ACM to adult ICU patients [10]. ACM-derived IAP agreed well with IVP technique in elevated IAP up to $17 \mathrm{mmHg}$ [10]. While these four landmark studies either applied IGP measurements via self-made devices, or used ACM placed intra-abdominally instead of intra-gastrically, Wauters et al. were the first who combined ACM with IGP determination in an animal model. Validated against an intra-abdominally placed fluid-filled catheter, ACM-IGP revealed excellent accuracy [16]. These encouraging data all motivated us to move from animal to clinical setting to conduct the first validation study using ACM with intra-gastric placement in a large setting of critically ill children presenting high IAH prevalence.

\section{Clinical implications}

Both measurement methods reflect the IAP very accurately and are well tolerated in clinical practice. Handling of an ACM-IGP catheter is similar to that of a conventional 
nasogastric tube and therefore theoretically bears a comparable risk profile (malposition with aspiration, pneumonia, pneumothorax and esophageal or gastric perforation) $[23,24]$. Nevertheless, to date, none of such complications have been published for the ACM-IGP system, nor have they been reported to the manufacturer nor were experienced in our institution in the last several years during multiple usage.

From a practical point of view ACM-IGP has the advantage that no infection-endangering bladder filling is necessary for IAP measurement $[25,26]$. In addition, patient safety is enhanced by the fact that (1) the measurement is continuous; (2) medical staff is relieved; (3) the measurement method is more widely accepted due to its clinicalpractical advantages, and (4) as a result of the more regular monitoring, IAP increases can be detected at an earlier stage and treated adequately in time. An earlier diagnosis of IAH in combination with a standardized therapeutic regime has recently shown to reduce the incidence of ACS from 10 to $2 \%$ in critically ill adults. The ACM-IGP method could facilitate the development and widespread implementation of a standardized diagnostic-therapeutic algorithm to reduce the incidence and morbidity of IAH and ACS in critically ill patients.

\section{Limitations of the study}

For secondary and exploratory analyses, we pooled all longitudinal paired measurements, disregarding the fact that some were taken from identical individuals. We consider this as plausible since patient conditions varied much during ICU stay, regarding vital signs, vascular pressures, respiratory status, sedation levels and many other factors. The variations introduced by these different condition combinations outweigh the fact that they derive partly from the same patients. The results of the primary, secondary and exploratory analyses showed no relevant differences. Both addressed and non-addressed influencing factors were therefore not able to impair the strong measurement agreement between both methods.

\section{Conclusion}

Our data allow the conclusion that both methods, IVP and ACM-IGP, reflect the IAP equally well. From clinical-practical and theoretical considerations, ACM-IGP may have advantages over the IVP technique.

With the help of this continuous monitoring method, timely diagnosis could be made easier and an adequate therapy could be initiated earlier in the future. Further prospective multicenter studies will be necessary to confirm the potential benefits of ACM-IGP in IAH diagnosis and therapy.

\footnotetext{
Abbreviations

ACM-IGP: Air capsule nasogastric tube; ACS: Abdominal compartment syndrome; Ch.: Charriére; CPAP: Continuous positive airway pressure; IAH: Intra-abdominal hypertension; IAP: Intra-abdominal pressure; IGP: Intra-gastric pressure; IVP: Intra-vesical pressure; LOS-PICU: Length of stay at paediatric intensive care unit; MHH: Hannover Medical School; PICU: Paediatric intensive care unit; PRISM-III-Score: Paediatric Risk of Mortality III Score; WSACS: World Society of Abdominal Compartment Syndrome (recently re-named as: The Abdominal Compartment Society).
}

\section{Supplementary Information}

The online version contains supplementary material available at https://doi.org/10.1186/s40635-021-00386-8. 
Additional file 1: Continuous Intra-Gastral Monitoring of Intra-Abdominal Pressure in Critically ill Children - A Validation Study.

\section{Acknowledgements}

Special thanks go to all children and parents for their willingness to participate in our study. Furthermore, we would like to thank our multidisciplinary PICU team for their great support, cooperation and assistance at all times. Many thanks to the cardiothoracic technicians of the Clinic for Cardiothoracic-Vascular Surgery of Hannover Medical School, who provided the equipment for the development of the container model.

\section{Authors' contributions}

TK carried out the experimental design, conceived and realised the overall research project. PB, MB and TK developed the study design of the in vitro experimental approach. MB, MG, AvG, HK, TJ and TK carried out the experiments, collected and analysed the data. Biometric analyses were conducted under the supervision of DB and FL. PB, MB, MG and TK drafted a first version of the manuscript. All authors contributed to revising the manuscript. All authors read and approved the final manuscript.

\section{Funding}

Open Access funding enabled and organized by Projekt DEAL. The study was financed by an in-house Grant (MHH Clinical-Scientist Program).

\section{Availability of data and materials}

Raw data and research results can be obtained from the authors upon reasonable request.

\section{Declarations}

\section{Ethics approval}

This study was performed in line with the principles of the Declaration of Helsinki. Approval was granted by the Ethics Committee of Hanover Medical School (No. 6677). The trial was registered internationally (WHO-ICTRP-NO. DRKS00006556).

\section{Consent to participate}

Written informed consent was obtained from the legal guardians.

\section{Consent for publication}

All test persons or their guardians agreed to the publication.

\section{Competing interests}

None of the authors has to declare any conflict of competing interest.

\section{Author details}

${ }^{1}$ Department of Paediatric Cardiology and Intensive Care Medicine, Hannover Medical School, Hannover, Germany. ${ }^{2}$ Institute of Biometry, Hannover Medical School, Hannover, Germany. ${ }^{3}$ Department of Paediatric Surgery, Hannover Medical School, Hannover, Germany. ${ }^{4}$ Department of Paediatric Cardiology and Intensive Care Medicine, Hannover Medical School, University Children's Hospital, Carl-Neuberg-Str. 1, 30625 Hannover, Germany.

Received: 7 December 2020 Accepted: 7 April 2021

Published online: 24 May 2021

\section{References}

1. Kirkpatrick AW, Roberts DJ, De Waele J et al (2013) Intra-abdominal hypertension and the abdominal compartment syndrome: updated consensus definitions and clinical practice guidelines from the World Society of the Abdominal Compartment Syndrome. Intensive Care Med 39:1190-1206. https://doi.org/10.1007/s00134-013-2906-z

2. Carlotti AP, Carvalho WB (2009) Abdominal compartment syndrome: a review. Pediatr Crit Care Med 10:115-120 https://doi.org/10.1097/PCC.0b013e31819371b2

3. Newcombe J, Mathur M, Ejike JC (2012) Abdominal compartment syndrome in children. Crit Care Nurse 32:51-61. https://doi.org/10.4037/ccn2012761

4. Kaussen T, Steinau G, Srinivasan P, Otto J, Sasse M, Staudt F, Schachtrupp A (2012) Recognition and management of abdominal compartment syndrome among German pediatric intensivists: results of a national survey. Ann Intensive Care 2(Suppl 1):S8-S8. https://doi.org/10.1186/2110-5820-2-S1-S8

5. Sugrue M, Bauman A, Jones F et al (2002) Clinical examination is an inaccurate predictor of intraabdominal pressure. World J Surg 26:1428-1431. https://doi.org/10.1007/s00268-002-6411-8

6. Kirkpatrick AW, Brenneman FD, McLean RF, Rapanos T, Boulanger BR (2000) Is clinical examination an accurate indicator of raised intra-abdominal pressure in critically injured patients? Can J Surg 43:207-211

7. Steinau G, Kaussen T, Bolten B, Schachtrupp A, Neumann UP, Conze J, Boehm G (2011) Abdominal compartment syndrome in childhood: diagnostics, therapy and survival rate. Pediatr Surg Int 27:399-405. https://doi.org/10.1007/ s00383-010-2808-x

8. Popescu GA, Bara T, Rad P (2018) Abdominal compartment syndrome as a multidisciplinary challenge. A literature review. J Crit Care Med (Targu Mures) 4:114-119. https://doi.org/10.2478/jccm-2018-0024 
9. Malbrain ML, De Laet I, Viaene D, Schoonheydt K, Dits H (2008) In vitro validation of a novel method for continuous intra-abdominal pressure monitoring. Intensive Care Med 34:740-745. https://doi.org/10.1007/s00134-007-0952-0

10. Otto J, Kaemmer D, Biermann A, Jansen M, Dembinski R, SchumpelickV, Schachtrupp A (2008) Clinical evaluation of an air-capsule technique for the direct measurement of intra-abdominal pressure after elective abdominal surgery. BMC Surg 8:18. https://doi.org/10.1186/1471-2482-8-18

11. Potter De, Tom JR, Dits H, Malbrain MLNG (2005) Intra- and interobserver variability during in vitro validation of two novel methods for intra-abdominal pressure monitoring. Intensive Care Med 31:747-751. https://doi.org/10.1007/ s00134-005-2597-1

12. Pollack M, Holubkov R, Funai T et al (2016) The pediatric risk of mortality score: update 2015. Pediatr Crit Care Med 17:2-9. https://doi.org/10.1097/PCC.0000000000000558

13. Goldstein B, Giroir B, Randolph A, International Consensus Conference on Pediatric Sepsis (2005) International pediatric sepsis consensus conference: definitions for sepsis and organ dysfunction in pediatrics. Pediatr Crit Care Med 6:2-8. https://doi.org/10.1097/01.PCC.0000149131.72248.E6

14. Kron IL, Harman PK, Nolan SP (1984) The measurement of intra-abdominal pressure as a criterion for abdominal reexploration. Ann Surg 199:28-30. https://doi.org/10.1097/00000658-198401000-00005

15. Schachtrupp A, Tons C, Fackeldey V, Hoer J, Reinges M, Schumpelick V (2003) Evaluation of two novel methods for the direct and continuous measurement of the intra-abdominal pressure in a porcine model. Intensive Care Med 29:1605-1608. https://doi.org/10.1007/s00134-003-1847-3

16. Wauters J, Spincemaille L, Dieudonne AS, Van Zwam K, Wilmer A, Malbrain ML (2012) A novel method (CiMON) for continuous intra-abdominal pressure monitoring: pilot test in a pig model. Crit Care Res Pract 2012:181563. https:// doi.org/10.1155/2012/181563

17. De Waele JJ, Cheatham ML, Malbrain MLNG, et al. Recommendations for research from the International Conference of Experts on Intra-abdominal Hypertension and Abdominal Compartment Syndrome. Acta Clin Belg. 2009;64:2039. 10.1179/acb.2009.036

18. Bland JM, Altman DG (1986) Statistical methods for assessing agreement between two methods of clinical measurement. Lancet 1:307-310. https://doi.org/10.1016/S0140-6736(86)90837-8

19. de Myttenaere A, Golden B, Le Grand B, Rossi F (2016) Mean absolute percentage error for regression models. Neurocomputing. https://doi.org/10.1016/j.neucom.2015.12.114

20. Wesley JR, Drongowski R, Coran AG (1981) Intragastric pressure measurement: a guide for reduction and closure of the silastic chimney in omphalocele and gastroschisis. J Pediatr Surg 16:264-270. https://doi.org/10.1016/s00223468(81)80677-x

21. Davis P, Koottayi S, Taylor A, Butt W (2005) Comparison of indirect methods of measuring intra-abdominal pressure in children. Intensive Care Med 31:471-475. https://doi.org/10.1007/s00134-004-2539-3

22. Yong SB, Ma JS, Chen FS, Chung MY, Yang KD (2016) Nasogastric tube placement and esophageal perforation in extremely low birth weight infants. Pediatr Neonatol 57:427-430

23. Metheny NA, Meert KL, Clouse RE (2007) Complications related to feeding tube placement. Curr Opin Gastroenterol 23:178-182. https://doi.org/10.1097/MOG.0b013e3280287aof

24. Dellimore KH, Helyer AR, Franklin SE (2013) A scoping review of important urinary catheter induced complications. J Mater Sci Mater Med 24:1825-1835. https://doi.org/10.1007/s10856-013-4953-y

25. Ejike JC, Bahjri K, Mathur M (2008) What is the normal intra-abdominal pressure in critically ill children and how should we measure it? Crit Care Med 36:2157-2162. https://doi.org/10.1097/CCM.0b013e31817b8c88

26. Cheatham ML, Safcsak K (2011) Intra-abdominal hypertension and abdominal compartment syndrome: the journey forward. Am Surg 77(Suppl 1):S1-5

\section{Publisher's Note}

Springer Nature remains neutral with regard to jurisdictional claims in published maps and institutional affiliations.

\section{Submit your manuscript to a SpringerOpen ${ }^{\circ}$ journal and benefit from:}

- Convenient online submission

- Rigorous peer review

- Open access: articles freely available online

- High visibility within the field

- Retaining the copyright to your article

Submit your next manuscript at $\boldsymbol{\nabla}$ springeropen.com 